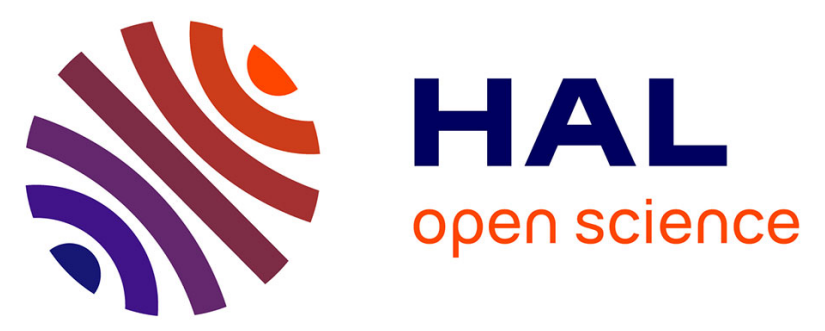

\title{
A Local Perspective: Working an Agricultural Information Service into a Rural Community
}

Lars Rune Christensen, Hasib Ahsan, Mamunur Rashid, Badal Kumar Das

\section{To cite this version:}

Lars Rune Christensen, Hasib Ahsan, Mamunur Rashid, Badal Kumar Das. A Local Perspective: Working an Agricultural Information Service into a Rural Community. 15th International Conference on Social Implications of Computers in Developing Countries (ICT4D), May 2019, Dar es Salaam, Tanzania. pp.267-279, 10.1007/978-3-030-19115-3_22 . hal-02281292

\section{HAL Id: hal-02281292 \\ https://inria.hal.science/hal-02281292}

Submitted on 9 Sep 2019

HAL is a multi-disciplinary open access archive for the deposit and dissemination of scientific research documents, whether they are published or not. The documents may come from teaching and research institutions in France or abroad, or from public or private research centers.
L'archive ouverte pluridisciplinaire HAL, est destinée au dépôt et à la diffusion de documents scientifiques de niveau recherche, publiés ou non, émanant des établissements d'enseignement et de recherche français ou étrangers, des laboratoires publics ou privés.

\section{(c)(1)}

Distributed under a Creative Commons Attribution| 4.0 International License 


\title{
A Local Perspective: Working an Agricultural Information Service into a Rural Community
}

\author{
Lars Rune Christensen (IT University of Copenhagen, Lrc@itu.dk) \\ Hasib Ahsan (IT University of Copenhagen, hahs@itu.dk) \\ Mamunur Rashid (Welthungerhilfe, mamunur.rashid@welthungerhilfe.de) \\ Badal Kumar Das (mPower Social, badal@mpower-social.com)
}

\begin{abstract}
Accounting for the ways in which ICT initiatives are worked into local communities is part of rendering "the local perspectives" within ICT4D. This paper is part of that. Based on in-depth fieldwork, we investigate the integration of an agricultural information service into a rural community in Bangladesh. We find that it takes work beyond the initial design and cursory introduction of the service to make the service work in a low-income rural community: it takes the strength of the farmers self-help groups to circulate the messages by word-ofmouth, it takes posters placed at key junctions according to a sociogeographic understanding of the village manifest in a map, and it (ideally) involves the support of the elite of the community via the broadcast of messages at places of high symbolic value. It takes all this in addition to a well-made information service delivering relevant and timely messages on for example agricultural matters. Hence, reducing the issue to one of technical delivery mechanism does not tell the full story.
\end{abstract}

\section{Keywords}

ICT4D; agricultural information services; mobile agricultural advice; appropriation; technology; field study. 


\section{Introduction}

Information and communication technology enabled services has the potential to increase the reach of for example agricultural extension by providing agricultural advice to smallholder farmers in the Global South [12]. Previous studies have presented and examined the different forms that such agricultural services may take, ranging from mobile services [7, 16], to radio [4, 14] as wells as Internet portals [2, 3]. These studies, then, suggests that farmers in the Global South can benefit from agricultural information services receiving, e.g. agricultural advice, market information, and actionable information on local climate. However, these studies rarely focus on describing, in detail, the cooperative work of making these services work locally. Making the agricultural information service usable for the farmers may take considerable work and may only be achieved as it becomes embedded into a wider, trusted, socio-technical ecosystem. In the words of Donovan "technology cannot be airdropped into a situation and guarantee positive results” [9, p.57]. This is because technology is not really technology until it is part of a living practice [6]. Generally speaking, research in HCI and HCI4D may (ideally) report on local experiences of adapting and implementing technology, including on how it may be made to work locally [21]. In this paper, we aim to contribute to this agenda. Knowledge emerging from explicitly local or indigenous perspectives, approaches and experiences with ICT in the Global South has not yet become substantial within ICT4D and HCI4D [1]. Indeed, there is a lack of research detailing, for example, the cooperative work of making technological initiatives work in disadvantaged communities in the Global South. Arguably, this is a piece of the puzzle that is crucial to understanding why some initiatives thrive where others fail.

In this paper, we report from a field study of the integration of an agricultural information service into a rural community in Bangladesh. We report from the CAIS project designed and implemented by Welthungerhilfe, mPower-Social, MMS, and FIVDB. Welthungerhilfe is an international, German based, aid organization, mPower-Social specializes in ICT interventions for development, whereas MMS and FIVDB are local non-governmental organizations specialized in aid work. In the paper we examine the cooperative efforts that enable smallholder farmers to benefit from an agricultural information service; 
we investigate how the agricultural information service is worked into a wider socio-technical ecosystem. Our findings show that it took concerted effort past the initial design and introduction of the service to make the service work for the community: it took the drive of the farmers self-help groups to circulate the messages by word-of-mouth, it took posters placed at key locations according to a socio-geographic mapping of the village, and it (partly) involved the support of the elite of the community via the broadcast of messages at places of high symbolic value - although this was soon discontinued. It took all this in addition to a well-made information service delivering relevant and timely messages on agricultural matters to make the service work locally.

The paper will proceed as follows. First, we will consider related research. Secondly, we will turn to the field setting and the methods of the study. Third, we present an analysis of the integration of the agricultural information service into the rural community in question. Fourth, we will provide a discussion and concluding remarks.

\section{Related research}

Agricultural information services in the global south typically aim to overcome the shortfalls of information within smallholder rural communities by supplementing local knowledge with (expert) agricultural advice, local weather forecasts, or local market prices for agricultural products, or some combination of the three [9, 12]. For example, the Knowledge Help Extension Technology Initiative (KHETI) in Madhya Pradesh, India, was used to raise awareness of agricultural extension services among farmers by providing them with mobile phones with short dialogues and videos [10]. Another example is Gandhi et al. [17], who developed Digital Green in India to provide targeted agricultural advice to farmers via video. Using a comparative experimental design, the authors found that Digital Green users had higher adoption rates for certain agricultural practices as compared to conventional extension approaches used by another group of farmers. Christensen et al. [7] examine the use of an agricultural advice service using voice messages pushed to the farmers feature phones synchronised with the growth stages of their crops. In addition, Patel et al. [16] developed a voice message forum to foster the creation of 
online communities of farmers sharing advice and local knowledge. Some messages were on weather-related issues, others on pest control, irrigation, fertiliser use, and the crops cycles in general. The authors found that the farmers were mainly interested in (expert) technical agricultural advice, thereby suggesting the need for such advice. Other initiatives have focused on improving the bargaining power of smallholder farmers vis-à-vis traders by servicing them with market information for example by sending text messages with price information on several nearby markets [12] - thereby ideally providing farmers with an informed choice on where to sell their produce. A key assumption of these services is that addressing a key market failure that of imperfect information - will help poor rural populations sell their produce at higher prices [3, p.43]. While some studies have noted that access to markets information services actually have improved the livelihood of farmers, other studies have found that the lack of trust in unfamiliar traders, road distances, and long-standing ties with dominant traders, often weight heavy on the farmers decision making when it comes to deciding where to sell their produce [9].

ICT initiatives may vary not only in terms of the types of agricultural services and the information they provide but also in terms of the human and institutional support that they are associated with. The least supported services offer access to voice-based or text-based databases of information regarding agricultural practice, weather predictions, or market prices - but no additional support. More integrated services may offer in-person technical and agricultural training, support by phone, or support through e-learning programs [3]. Some services are part of a larger socio-technical environment comprised of, e.g. physical facilities, human expert advisers, and access to agricultural inputs. For example, the eChoupals initiative, operating in Madhya Pradesh in India, provides market prices and weather information integrated with crop transportation facilities, weighing and storage, and payment system (Kumar 2004). Another service is Grameen Foundations Community Knowledge Worker initiative in Uganda, which equips extension agents with smartphones to act as community agents of agricultural information [13].

The above studies, then, suggests that farmers in the Global South can benefit from agricultural information services receiving agricultural advice, market information, and actionable information on local 
climate. However, these studies rarely focus on describing in detail the cooperative work of making these services work locally. Making the agricultural information service usable for the farmers may take considerable work and may be achieved only as it becomes embedded into a wider, trusted, socio-technical ecosystem. To reiterate, there is a lack of research detailing the cooperative work of making technological initiatives work in disadvantaged communities in the Global South. However, one notable effort to fill this gap, albeit outside ICT for agriculture, includes O’Neill et al.'s [15] ethnographic investigation of the work of making a new digital loan payment service for autorickshaw drivers work in Bangalore, India. O’Neil et al. [15] describe how making the service useful took considerable cooperative work on the part of not only the drivers but also on the part of the employees of the local NGOs. It was largely achieved because the initiative was embedded into a wider established setting, and because of the commitment and work of the human actors within that setting. We take inspiration from this study.

\section{Methods and setting}

We conducted the field study of the practices associated with the introduction and use of the agricultural information service over a period of six months in late 2017 and early 2018. We conducted participatory observation and carried out six in-situ semi-structured interviews as well as three focus groups. The participatory observation was conducted mainly by the second author, while the focus groups and interviews, and a lesser part of the observations, was conducted jointly by the two authors. The focus groups with the farmers included questions on education; family; community; village life; financial circumstances; income; climate; farming; and their experiences with the agricultural information service. The interviews were conducted in Bangla, the language of Bangladesh. We conducted six semi-structured interviews with NGO staff and local government officials. The interviews with the NGO staff included questions on background; work experience; the NGO; relationships with farmers; village life; climate; and their experiences with the agricultural information service. We conducted observations of the use of the service in the villages. This included accompanying the NGO staff working in the villages during their employment of the information service, and it included being with 
the farmers as they used the service, shared and talked about the information, and farmed their land.

The data was recorded through extensive field notes, audio recordings and photographs. The interviews were translated and transcribed. Our analysis took a broadly practice-oriented perspective [5, 6, 8, 20, 22] with inspiration from ethnomethodology $[11,18]$. Practice studies, in our perspective, explicate how participants organise their practice and emphasise the ways in which technologies and artefacts are an integral and indispensable part of the accomplishment of that practice. The authors read through and discussed the data in various analytical session in person and on Skype. The data was organised into themes as topics emerged from the analytical sessions. A concerted effort was made to have the themes, and in turn, the findings emerge from the data itself.

The geographical setting of our study is part of the Chalan Beel wetland in the Sirajgonj District of Bangladesh. Surveys typically classify Bangladeshi smallholder farmers in this area as poor or extremely poor [19]. Smallholders typically earn minor amounts on a seasonal basis depending on crop yields and prices. In addition to relying on their farms for financial income, the farmers in our study depend on their agricultural output for sustenance. Low crop yields, or outright crop failures, therefore represent a serious challenge to the farmers. During flooding or other agricultural crisis, the male household member often seeks alternative employment such as running a local tea stall or operating a rickshaw on the mainland. However, this alternative selfemployment is typically inadequate in terms of supporting a household of often ten members or more. Some of the households that were part of our study were struggling.

\section{Working an ICT initiative into a rural community}

It is little more than a truism that working an ICT initiative into the fabric of a rural community in the Global South requires collaborative work and effort. Relatedly, the interesting point is what kind of work it takes, whose work, what the modalities of this work are, and what social and technical infrastructure is it based on. We may dub such efforts integration work. These are the themes that we address below. 
However, before doing so, it is timely to introduce the design of the agricultural service alluded to above.

\section{The design of the agricultural information service}

As indicated above, the service in question is a mobile service that delivers agricultural information to the handsets of smallholder farmers in Bangladesh. It was developed in a collaboration between mPower, the technical partner, the farmers and the local NGO called MMS. All funded by the German NGO Welthungerhilfe. During the development, mPower, the technical partner, visited the field site twice and facilitated a co-design process with representatives of the farming community together with the local NGO team. In this process it was agreed that the service should support smallholder farmers by (1) assembling weather forecasts from the public domain for the specific village locations, (2) associate agricultural advice with the weather forecasts, and (3) send text messages to the farmers with the weather forecasts and the associated agricultural advice. The rationale for this new service was that smallholder farmers in remote rural areas do not have access to such information. The governmental agricultural extension service does not have the resources to visit the farmers on the Char islands. Not only is the public agricultural extension service understaffed and underfinanced, it is also considered somewhat dangerous for the extension officer to visit the Char islands. In addition, there is no electricity on the Char islands other than one or two solar panels per villages. These are mainly used for charging mobile phones. Nobody owns a TV set. Hence, the farmers in the area do not have access to local weather forecasts, nor do they have access to expert agricultural advice.

The service was designed to send SMS messages to 250 farmers once a week during normal conditions and up to three times a week during disasters such as flooding. To make the service operational, basic data on the names of the farmers, their mobile phone numbers, crop types, crop stages, and more had to be collected by MMS and entered into the system. In addition, an initial series of alert types had to be created by agricultural experts working for the project. That is, for each crop types, crop stage, and weather condition an appropriate message for the 
farmers had to be created. Here is an example of a message sent by the service:

\begin{abstract}
A cold wave with heavy fog may occur in your area in the next 2-3 days. During that time, to protect your tomato plants from fungal attack spray fungicide (Dithene M-45) onto the plants. Use $20 \mathrm{mg}$ in 10 liters of water for every 5 decimals of land. (SMS sent 2nd Jan 2018)
\end{abstract}

Another example of the content of the service is a message which is also concerned with the prevailing cold weather and fog in the area. The concern here again springs from the fact that fog may leave dew on the leaves that in cold weather may lead to fungus. A method of removing the dew drops is advised:

The mild cold wave with heavy fog will continue this week too. Due to cold weather do not irrigate in the sweet gourd field at the flowering stage but do mulching. Remove dew (fog) from the upper leaf of the Boro rice plants by using a string moving across the field. (SMS sent 14th Jan 2018)

The designers of the service mapped the connections between crops type, crop stage, DAS stage, weather condition, threshold values, and SMS message texts. First, a list of priority crops was selected by the farmers in collaboration with the NGO field staff. Subsequently, a list of adverse weather conditions was drawn up defined by threshold values. The idea being that if real-life conditions at a given time meet the values of a defined "adverse weather condition" then the associated set of SMS messages would be sent to the farmers. The messages sent to 500 farmers designate as "lead farmers", i.e. those individuals leading a particular village self-help group. The lead farmers would receive only those SMS messages that pertained to his or her group, that is, their crop types and the stages of these crops. This logic required MMS staff to record data on the lead farmers (i.e. name, location, phone number, group) and record and update data on the groups continuously (i.e. crops types, sowing dates, and crop development). If was important to have accurate data on these items for the service to be able to function as planned. This data work was assigned to MMS staff. 
Having presented the service, and the basic features of it, we are now in a position to consider how it was worked into the fabric of village life.

\section{Word-of-mouth}

At first, the main village studied resembled any other village in the Charlands of rural Bangladesh that the authors had visited during their stay in the Sirajgonj district. Yet, from talking to the villager's something about its organisation stood out. Assisted by the local NGO, the villagers had organised themselves into self-help groups each comprised of about ten farmers with one of the farmers acting as 'lead farmer' for the group. The lead farmer was someone with a certain standing in the local community and was, without exception, the owner of a mobile phone. Far from all the farmers in a self-help group owned such a device.

A shared consensus among the farmers, that village life benefitted from these groups, emerged from conversation. The self-help groups had mapped the village, created a savings scheme, and acted as conduits for the information delivered by the agricultural information system. The lead farmer of the group would receive the messages from the service and in turn relay the advice to the rest of the group (most of which had no phone). This oral retelling of the advice created a word-of-mouth network, where the lead farmer would tell one or two other farmers from her group, and these farmers would, in turn, tell other group members, and perhaps also the neighbours, and so on. In this manner, the advice would spread by word-of-mouth. Word-of-mouth would extend the digital infrastructure of the agricultural information service. This was necessary to reach more farmers.

During this process of retelling, of relaying the advice from the phones of the few to the ears of the many, the information would be contextualised through conversation, it would be interpreted, and instructive conversation sparked by the information would emerge.

"I could not at first understand the message about the fertiliser, but she explained it to me, and showed me how to mix the fertiliser and the water right." 
By word-of-mouth the information from the service would be retold, lead to instruction and learning, and in this manner be far more valuable than mere 'objective' relaying of the messages could ever be. The point is that the engaged retelling of the information by the members of the self-help groups improved the service, it added value to the service. This is because the retelling created opportunities for conversation, instruction, and collaborative learning. This would happen, for example, in relation to understanding the use of fertiliser as the quote above indicates, and it would happen in relation to learning new farming techniques such as the removal of dew from plants to avoid fungus. One message from the service reads like this on a mobile phone:

The mild cold wave with heavy fog will continue this week too. Due to cold weather do not irrigate in the sweet gourd field at the flowering stage but do mulching. Remove dew (fog) from the upper leaf of the Boro rice plants by using a string moving across the field. (SMS sent 14th Jan 2018)

Figuring out how exactly to move a cotton string across a rice field to drop dew from rice plants is not obvious if you have not tried it before a farmer told us. The retelling of a message, such as the one above, by one farmer to another may create a collaborative learning situation where the two farmers in collaboration figure out how this is done, or if need be, ask for further assistance from for example the lead farmers, who have often been educated in farming techniques by the local NGO. Another matter for deliberation among the farmers is the accuracy of the weather forecasts which were often part of the messages as seen above. On one occasion the weather forecast was off (as such forecasts occasionally are), that is, the message had predicted heavy morning fog, and the farmers had taken precautions by covering up some of their plants to lessen the risk of fungus, but in the morning no fog. This situation prompted some good-humoured mockery of the NGO staff by the farmers. The NGO staff who had introduced the service was seen as vouching for it, as responsible for it. When weather predictions were right, it would lead to praise of the NGO staff by for example farmers asking - half in jest and half in earnest - "are you some sort of magicians?". And when the predictions were off it would as mentioned lead to good-humoured taunts. This goes to show the degree to which 
the local NGO staff were strongly identified with the service that they introduced to the farmers (but only in part designed).

The weather predictions were more often right than wrong, and the farmers ended up mostly adhering to them, as ignoring them could have serious or even devastating consequences for their crops. Taking precautions against adverse weather such as fog (covering plants), or heavy rain (digging rain gutters), was at worst a waste of time if the weather forecast was wrong. It was not a disaster as ignoring the weather forecast might be as fungus-induced by fog or rain might take the plants. In this manner, there was a certain economy of practice is adhering to the weather forecasts, rather than ignoring them. The prediction of rain may also save on irrigation, but if the rain does not come, the plants are at risk of drying out. So, there is something at stake, and therefore the messages were often the object of reflection, conversation, and deliberation, rather than something which was followed 'mechanically'.

\section{Posters}

Another way of reaching those without phones where through posters placed at central spots in the village. Posters were most often handcrafted by the lead farmer, or NGO staff, and displayed the (phone) messages that were deemed to be of special importance to the farmers.

Messages where at times, though not always, placed at spots where they were especially relevant. For example, messages about the risk of flooding were placed at flood-prone areas, posters on the risk of fog were placed where fog might gather, and messages about certain crops were placed at their fields. It emerged from conversations that the farmers had very good knowledge of the layout of the village. The farmers pointed to the collaborative creation of maps as contributing towards this understanding. Let us elaborate. 


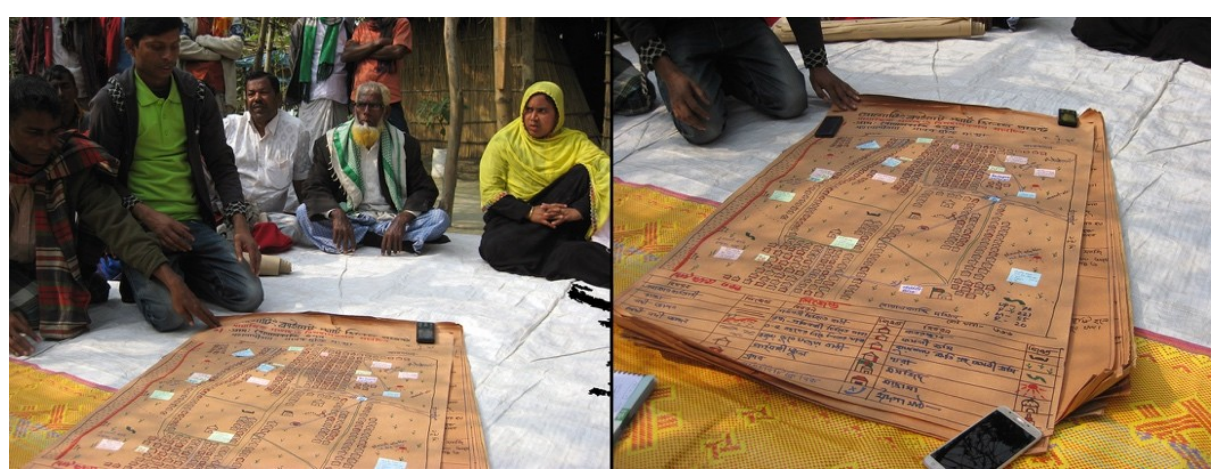

Figure 1: Map of the village made by local farmers in collaboration with MMS the locally active NGO. The map roughly represents an area of $2,25 \mathrm{~km}^{2}$.

The farmers had in collaboration with the local NGO created a map of the village which depicted the village, its households, and it (ecological) vulnerabilities (see figure 1). Lowland and saline-prone areas were singled out on the map as potential trouble spots. That is, areas that called for vigilance and a concerted collective effort. In addition, all the households were shown and given a number for easy reference on the map. Furthermore, important structures such as the village Mosque and the local boat mooring site is also shown. The map shows all 366 households of the village, it shows what kind of crops are planted where, and it shows what areas are flood-prone, what areas are drought-prone, and where fog may gather. Furthermore, it contains information on the quality and nature of the soil that are important parameters for agriculture. Furthermore, colour codes are used to designate households with for example pregnant women or children under the age of five. Both being indicators of a vulnerable household someone to "look extra out for". Every six months or so the maps where to be updated - to reflect the development in each household and each crop field if any.

This mapping of the village, this sense of place, was used by both those (lead) farmers that placed the posters and by those farmers that subsequently read them. The digital information service was extended by the posters, then, and in this work of integrating the advice into the fabric of the villages the maps played an important role as enabler. For example, from looking at the map, it was readily apparent to the farmers that messages concerning maize cultivation, maize pests, and maize diseases belong next to the maize fields. While, messages 
concerning fog were relevant to those farming the fields where the morning fog gather, and so on. In this manner (some of) the advice and forecasts stemming from the service were 'plotted onto the village map' and in the process gathered more meaning and significance. For whom, what, or where a message might be relevant was partly settled with the help of the village map. Not necessarily by overtly pointing to the map but more often by reference to the knowledge that the making of the map had created.

That the map of the village, and the knowledge made in the process of producing it, became a frame for appreciating the messages testifies to the importance of framing. That is, we may argue that the (fruitful) reception of the messages was in part due to the villagers own high level of self-understanding and appreciation of their situation which was (partly) generated in spatial terms via the map and mapping process. We should not overemphasise the importance of the map as an artefact but rather recognise the process of making the map as a contribution to the villages self-understanding and by extension also to their sense of community and solidarity.

The map, then, in its many incarnations and versions, is not a traditional map for travel, locomotion or navigation. Rather, the map is a depiction of the socio-spatial configuration of the village, including the vulnerabilities of the farmers, including their flood-prone fields, their drought-prone fields, their saline soil, and places where fog may gather and in turn fungus may appear. Moreover, one can see the placement of the posters as a direct extension of this mapping, this spatial view of the village. The poster was placed, assigned places, in accord with the villagers' socio-spatial knowledge of themselves and their lifeworld. Placing a poster well, where the message might be needed, is a way to continue to manifest socio-spatial knowledge.

The map reaches out beyond the agricultural and includes as mentioned all households, with an emphasis on vulnerable families with children, has landmarks such as the mosque and more. The local mosque, in the midst of the village, was also central to the circulating of the messages as we shall see next. 


\section{Public announcements}

The village mosque lies at the centre of village life, metaphorically as well as physically. It is the spiritual, moral and religious epicentre of the village. Therefore, it was a blow to the project that the local Imam, after consideration, disallowed NGO staff's use of the mosque's PA system as a means to broadcast messages. The local Imam did not approve of the announcement of messages such as weather forecasts and associated agricultural advice, stemming from the service, in his mosque. The field officer assigned from the local NGO to the village comes every five days or so and was hoping to announce some messages and forecasts to the villagers using the mosque. Select messages on for example extreme weather predictions such as drought or flooding that may be considered important and even vital for the welfare of the village. And the NGO officer was hoping in the process to promote the service and the work of the NGO. A few messages were mic'ed in the Mosque - to use the expression of the NGO officer before this practice was discontinued.

Using the Mosque as a platform would have not only potential practical benefits - i.e. a large audience for the messages - but also symbolic significance. That is, by broadcasting from the Mosque, by using the mosque as a broadcasting platform, the legitimacy and status of the service would be heightened considerably according to the NGO staff. As mentioned, this was not to be as the practice was soon discontinued by the intervention of the Imam. By this act the reverse of what the NGO hoped for happened, that is, the legitimacy of the agricultural information service decreased in the eyes of the villagers. In conversation with the local field officers if became apparent that the support of the local elite, including the Imam, was important to the implementation of any development initiative, including the agricultural information service in questions here.

Although the Imam, then, denied the NGO the legitimacy associated with speaking the messages in the Mosque, the promotion of the service outside of the Mosque was tolerated by the Imam. He just preferred to reserve the Mosque for the excursive of religious practice.

The farmers, for their part, valued the weather forecasts. The records of the NGO show that approximately four out of five messages were accurate in terms of predicting the local weather. One has to keep in mind that prior to the introduction of the service the farmers had not 
experienced a digital service of this kind before. Previously their access to general regional weather forecasts was very limited as the village had no televisions nor radios. Mobile (feature) phones were the only communication technology available - and the village was without access to the Internet. Thus, information from beyond the island came with people coming and going to and from the village by boats and small ferries and by phone calls. Before the introduction of the service, accounts of the upcoming weather were anecdotal at best and based on regional forecasts that the travellers or commuting workers had seen or heard in the city perhaps the day before. In contrast, the weather forecasts of the service were local, rather than regional, and associated with agricultural advice such as "cover your tomato plants with plastic sheets due to upcoming heavy rain", or "dust your eggplants with ashes as fog is excepted tomorrow morning". One farmer told us that he lost almost an entire field of eggplants the year before the introduction of the service due to fungus infection, this year he spread ashes on the leaves to prevent morning fog from settling on the leaves, this, in turn, prevented the spreading of fungus and improved his yields. The farmers tell us that he hardly lost an eggplant to fungus this year. We heard many accounts like this. Obviously, the value of the service, especially in relation to crop yields, cannot be evaluated based on anecdotal evidence alone, and therefore we will make no sweeping claims regarding yields. Rather, we will suffice to say that it emerged through conversation that the farmers experienced the service as valuable and worthwhile.

Moreover, using the service can be characterised as a learning experience, rather than a mere 'consumption' of messages. For example, the technique of spreading ashes to prevent fungus was new to the farmers. It was something that they learned through the service, and through conversations with peers using the service. The farmers also learned to moderate their use of fertiliser and pesticides and thus save money, safe keep the environment, and improve crop yields. Just as they learned a number of other agricultural techniques associated with the crop cycle, weather, disease and pest prevention. In this manner, the experience of using the service, the outcome, was to a large extend educational. For example, once the farmers had learned that fog threatens fungus and that spreading ashes is the appropriate countermeasure against this threat, then this lesson had been learned, 
once and for all. That is, after having used the service for a while some of the advice associated with the weather forecasts became somewhat superfluous to some farmers. The weather forecasts in time became enough for those of the farmers that had learned the weather-related advice by hearth. They had, from engaging with the service, already learned the techniques and did not need to have them repeated. This testifies to the educational value of the service.

\section{Discussion and concluding remarks}

As mentioned in the introduction, research within HCI and HCI4D may (ideally) report on local experiences of adapting and implementing technology, including on how it may be made to work locally [21]. In this paper we have aimed to contribute to this agenda as knowledge emerging from explicitly local or indigenous perspectives, approaches and experiences with ICT in the Global South has not become substantial as of yet in our field [1]. Accounting for the work to make ICT work locally may arguably be a piece of the puzzle that is crucial to understanding why some initiatives thrive where others fail. Although all good technology may appear as magic to its users, none was involved in our case. Rather, it took hard work and a concerted collaborative effort to make the service work. To reiterate, our findings show that it took concerted effort beyond the initial design and cursory introduction of the service to make the service work in the community: it took the vigour of the farmers self-help groups to circulate the messages by word-of-mouth, it took posters placed at key placed according to a socio-geographic mapping of the village, and it involved the acceptance of the initiative by the community elite. It took all this in addition to a well-made information service delivering relevant and timely messages on agricultural matters to make the service work locally.

Our finding resonates with the work of O'Neill et al. [15] that emphasises the collaborative effort of working an ICT initiative into a community in the Global South. There are many differences between the two studies, e.g. urban vs rural, finance vs agriculture, and more. However, common is the acknowledgement that ICT initiatives do not sort themselves out by default, it takes work to make them work. This point echoes the slogan purported by Donovan, namely, that "new 
technology cannot be airdropped into a setting” [9]. The work to make ICT initiatives work, embed themselves, and become an integrated part of local practice may easily be overlooked. An agricultural information service in action may metaphorically speaking be described as a living and breathing entity, that needs nurturing, care, and legitimacy to work in a community. In the eyes of the users' legitimacy may be achieved through the demonstration of practical value as well as through more symbolic means - two distinct kinds of legitimacy.

\section{Acknowledgements}

We would like to acknowledge our indebtedness to Welthungerhilfe in Bangladesh, mPower (Mridul Chowdhury, Nazrul Islam, Masudur Rahman, Ahmed Sushmoy), MMS (Mr. Rafiq), and FIVDB. In addition we would like to warmly thank the farmers taking part in the study.

\section{References}

1. Abdelnour-Nocera, J. and M. Densmore, A review of perspectives and challanges for international development in information and communication technologies Annals of the International Communication Association, 2017. 41(3-4).

2. Aker, J.C., Dial "A" for agriculture: a review of information and communication technologies for agricultural extension in developing countries. Agricultural Economics, 2011. 42(6): p. 631-647.

3. Aker, J.C., I. Ghosh, and J. Burrell, The promise (and pitfalls) of ICT for agriculture initiatives. Agricultural Economics, 2016. 47(S1): p. 35-48.

4. Chapman, R., R. Blench, G. Kranjac-Berisavljevic, and A. Zakariah, Rural radio in agricultural extension: the example of vernacular radio programmes on soil and water conservation in N. Ghana. AgREN Network Paper, 2003. 127: p. 2.

5. $\quad$ Christensen, L.R., On Intertext in Chemotherapy: an Ethnography of Text in Medical Practice. Computer Supported Cooperative Work (CSCW), 2016. 25(1): p. 1-38.

6. Christensen, L.R., Techno-anthropology for Design, in What is Technoanthropology?, T. Børsen and L. Botin, Editors. 2014, Aalborg University Press: Aalborg.

7. Christensen, L.R., H. Ahsan, and E. Akand, Krishi Kontho: An Agricultural Information Service in Bangladesh, in NordiCHI'18, September 29-October 3, 2018, Oslo, Norway 2018, ACM.

8. Christensen, L.R. and R. Harper, H.R. , The Many Faces of Computational Artifacts, in COOP 2016: Proceedings of the 12th International Conference on the Design of Cooperative Systems, A. De Angeli, et al., Editors. 2016, Springer International Publishing. p. 93-106. 
9. Donovan, K., Anytime, Anywhere: Mobile Devices and Services and Their Impact on Agriculture and Rural Development, in ICT in Agriculture: Connecting Smallholders to Knowledge, Networks, and Institutions2017, World Bank Publications: Wasington. p. 49-68.

10. Fu, X. and S. Akter, The Impact of ICT on Agricultural Extension Services Delivery: Evidence from the Rural e-services Project in India., in TMD Working Paper Series No. 046.2012: University of Oxford, Department of International Development.

11. Garfinkel, H., Studies in Ethnomethodology1967, NY: Englewood Cliffs. 12. Heeks, R., Information and Communication Technology for Development (ITC4D)2018, London: Routledge.

13. McCole, D., M.J. Culberttson, M. Suvedi, and P.E. McNamara, Addressing the challenges of extension and advisory services in Uganda: The Grameen Foundation's community knowledge worker program. Journal of International Agricultural and Extension Education, 21(1), 6-18., 2014. 21(1): p. 6-18.

14. Nyareza, S. and A.L. Dick. Use of community radio to communicate agricultural information to Zimbabwe's peasant farmers. in Aslib Proceedings. 2012. Emerald Group Publishing Limited.

15. O’Neill, J., A. Dhareshwar, and S.H. Muralidhar, Working Digital Money into a Cash Economy: The Collaborative Work of Loan Payment. Computer Supported Cooperative Work (CSCW), 2017. 26(4): p. 733-768.

16. Patel, N., D. Chittamuru, A. Jain, P. Dave, and T.S. Parikh, Avaaj otalo: $a$ field study of an interactive voice forum for small farmers in rural india, in SIGCHI Conference on Human Factors in Computing Systems2010, ACM: Atlanta, USA. p. 733-742.

17. R. Gandhi, R. Veeraraghavan, a. K. Toyama, and V. Ramprasad., Digital Green: Participatory video for agricultural extension, in Information and Communication Technology and Development (ICTD 2007)2007: Bangalore.

18. Randall, D., R. Harper, and M. Rouncefield, Fieldwork for Design - Theory and Practice. Computer Supported Cooperative Work, ed. R. Harper2007, London: Springer.

19. Rapsomanikis, G., The Economic Lives of Smallholder Farmers 2015, Food and Agriculture Organization of the United Nations: Rome, Italy. .

20. Schmidt, K., Practice and Technology: On the Conceptual Foundations of Practice-Centered Computing, in Socio-informatics: A Practice-based Perspective on the Design and Use of IT Artefacts, V. Wulf, et al., Editors. 2018, Oxford University Press: Oxford. p. 47-104.

21. Suchman, L., Located accountabilities in technology production. Scandinavian Journal of Information Systems, 2002. 14(2): p. 91-105.

22. Wulf, V., V. Pipek, D. Randall, M. Rohde, K. Schmidt, and M. Stevens, Socio-informatics: A Practice-based Perspective on the Design and Use of IT Artefacts2018, Oxford: Oxford University Press. 